\title{
HUBUNGAN BUDAYA INDIVIDUALIS-KOLEKTIF DAN MOTIVASI BERBELANJA HEDONIK PADA MASYARAKAT KOTA JAKARTA
}

\author{
Devi Jatmika \\ Program Studi Psikologi Universitas Bunda Mulia \\ dephey@gmail.com
}

\begin{abstract}
Many shopping centers try to create an environment that makes consumers feel comfortable when they do shopping. Hedonic shopping motivation relates to contentment and enjoyment by shopping experience, it creates happiness feeling. Hedonic shopping motivation can not be separated from the role of culture in the society. This research aimed to know the relationship between individualist-collective culture with hedonic shopping motivation among people in Jakarta. The research used non ecperimental quantitative research. The data was collected by distributing hedonic shopping motivation and individualist-collective culture questionnaire. Total respondents in this research were 134 people. The results revealed collective culture (mean $=18.33)$ has higher mean rather than individualist culture (mean= 17.29). Statistic analysis with Spearman Coorelation, $r=0.187$ ad $p=0.031<0.05$. Meanwhile, individualistic culture showed no coorelation with hedonic shopping motivation, $r=0.164$ and $p=0.059>0.05$. Collective culture also had significant relationship with role shopping $(r=0.241, p=0.005)$, social shopping $(r=0.179, p=0.038)$ and value shopping $(r=0.241, p=0.042)$. The research concluded people in Jakarta tend to have collective culture. There was a relationsip between collective culture and hedonic shopping motivation, especially role shopping, social shopping dan value shopping.
\end{abstract}

Keywords: Hedonic Shopping Motivation, Culture, Collective Culture, Individualistic Culture

\begin{abstract}
ABSTRAK
Tempat- tempat perbelanjaan berusaha untuk menciptakan suasana agar konsumen betah berbelanja. Motivasi berbelanja hedonik berhubungan dengan senang dan nikmat yang diperoleh dari pengalaman berbelanja dan menghasilkan perasaan gembira. Motivasi berbelanja ini tidak terlepas dari peran budaya dalam masyarakat. Tujuan dari penelitian ini adalah untuk mengetahui hubungan budaya individualiskolektif terhadap motivasi berbelanja hedonik pada masyarakat di Jakarta. Penelitian ini menggunakan metode penelitian kuantitatif non eksperimental. Pengumpulan data dilakukan dengan menyebarkan kuesioner motivasi berbelanja hedonik dan kuesioner budaya individualis-kolektif. Jumlah responden dalam penelitian ini sebanyak 134 orang. Hasil penelitian menunjukkan nilai rata-rata budaya kolektif (mean= 18.33) lebih tinggi dibandingkan dengan nilai rata-rata budaya individualis (mean=17.29). Hasil uji statistik dengan uji korelasi Spearman, diperoleh hasil budaya kolektif berkorelasi signifikan dengan motivasi berbelanja hedonik, $\mathrm{r}=0.187$ dan $\mathrm{p}=0.031<0.05$, sedangkan budaya individualis tidak ada korelasi dengan motivasi berbelanja hedonik, $\mathrm{R}=0.164$ dan $\mathrm{p}=0.059>0.05$. Budaya kolektif juga diketahui berhubungan secara signifikan dengan role shopping $(\mathrm{r}=0.241, \mathrm{p}=0.005)$, social shopping $(\mathrm{r}=0.179, \mathrm{p}=0.038)$ dan value shopping $(\mathrm{r}=0.241, \mathrm{p}=0.042)$. Penelitian ini dapat disimpulkan masyarakat kota Jakarta memiliki kecenderungan budaya kolektif. Budaya kolektif berhubungan motivasi berbelanja hedonik terutama pada motif role shopping, social shopping dan value shopping.
\end{abstract}

Kata kunci:Motivasi Berbelanja Hedonik, Budaya, Budaya Kolektif, Budaya Individualis.

\section{PENDAHULUAN}

\subsection{Latar Belakang}

Pertumbuhan ekonomi yang semakin pesat di negara-negara berkembang termasuk Indonesia menciptakan gaya hidup yang berbeda dengan beberapa dekade sebelumnya. Fenomena yang terlihat sat ini adalah pertumbuhan masyarakat golongan kelas menengah di Indonesia. Bolton Consulting Group (dalam Mitra, 2014), mencatat pertumbuhan golongan kelas menengah di Indonesia pada tahun 2013 telah mencapai angka 74 juta orang. BCG juga telah memberikan prediksi bahwa pada tahun 2020, angka tersebut akan terus meningkat hingga mencapai 141 juta orang atau sekitar $54 \%$ dari total penduduk di Indonesia. 
Meningkatnya golongan kelas menengah, dipercaya membuat masyarakat Indonesia tidak takut dalam mengkonsumsi uang mereka untuk membeli berbagai macam barang yang diinginkannya (Mitra, 2014).

Pertumbuhan masyarakat ekonomi menengah diiringi dengan pertumbuhan penggunaan internet untuk berbelanja dan pusat-pusat perbelanjaan di kota. Bisnis belanja online ini disebut pula e-commerce. Presiden MasterCard untuk wilayah Asia Tenggara, menyatakan bahwa Indonesia merupakan salah satu negara dengan pertumbuhan pasar e-commerce yang terbesar di Asia Pasifik (dalam Mitra, 2014). Berdasarkan data lembaga riset ICD (dalam Mitra, 2014), pasar e-commerce di Indonesia akan mengalami pertumbuhan dari tahun 2012-2015 sebesar 42\%.

Hal lainnya adalah pertumbuhan mal-mal di Jakarta. Lamudi sebagai platform global merilis hasil penelitian pertumbuhan property ritel, diperoleh sebanyak 170 mall di kota metropolitan. Semua mal memiliki konsep yang sama yaitu memanjakan pengunjungnya, begitupula dengan kehadiran label- label high end, toko-toko dan restoran dari luar negeri maupun lokal memicu keinginan para konsumen untuk retail therapy. ("Jakarta, Kota dengan", 2014).

Persaingan dengan e-commerce membuat sektor yang menjual barang maupun jasa tradisional tidak hanya dengan mengandalkan pilihan merek dan produk yang beraneka ragam, harga yang murah, atau jam buka yang lebih panjang, namun dengan menciptakan suasana yang membuat konsumen betah untuk menghabiskan waktu dengan menciptakan suasana hedonik. Konsumsi hedonis merupakan kesenangan dan kenikmatan yang diharapkan oleh konsumen dari berbelanja. Harapan dari berbelanja berbeda-beda dari setiap konsumen, maka begitu juga perasaan yang dirasakan ketika berbelanja. Konsumsi hedonik sendiri bersumber dari hedonism. Secara filosofi hedonism diartikan sebagai pencarian rasa senang dalam hidup, walaupun hedonisme berkaitan dengan rasa senang, tidak terencana dan berlebihan, tetapi penting dalam dunia bisnis untuk mengetahui faktor-faktor apa yang memotivasi konsumen terhadap perilaku hedonis (dalam Bakirtas \& Divanoglu, 2013). Dengan memperhatikan faktor-faktor seperti kepuasan terhadap sensasi, memperoleh waktu yang menyenangkan, rasa ingin tahu, mendapatkan pengalaman baru, rasa bangga, rasa senang dengan orang lain, mendapatkan informasi dan perkembangan budaya akan memberikan keuntungan bagi bisnis dalam memahami perilaku konsumen untuk jangka panjang (dalam Bakirtas \& Divanoglu, 2013).

Studi yang dilakukan oleh Arnold dan Reynolds (2003) mengidentifikasi dimensi-dimensi daari motivasi belanja berdasarkan kesenangan yaitu, adventure, social, gratification, role, idea, dan value shopping motivation. Aspek hiburan menjadi senjata ampuh untuk mendorong konsumen berbelanja. Dalam penelitian yang dilakukan oleh Ertekin, Bayraktaroglu dan Gurkaynak (2014) di Turki ditemukan tidak ada hubungan antara usia dengan penilaian terhadap suasana yang memotivasi belanja hedonik, dengan kata lain usia muda maupun tua memiliki motivasi belanja hedonik. Tetapi, faktor sosial seperti penampilan, sikap dan pengetahuan karyawan adalah faktor penting untuk motivasi belanja hedonik. Dari sisi jender, menurut Tifferet dan Herstein (dalam Kusuma, Idrus, dan Djauzuli, 2013) ditemukan bahwa perempuan lebih hedonis dibandingkan laki-laki.

Dari paparan di atas telah diketahui dengan meningkatnya masyarakat golongan menengah, pertumbuhan kota terutama dengan arus bisnis yang tinggi di kota menciptakan gaya hidup baru yaitu berbelanja. Menurut data dari BPS tahun 2010 menunjukkan komposisi penduduk yang tinggal di kota semakin tinggi. Masyarakat kota yang disebut masyarakat urban adalah masyarakat terbuka dan cenderung individualis, nilai-nilai 
tradisional pelan tapi pasti akan semakin tergeser oleh budaya urban (Mazwahid, 2016). Masyarakat urban adalah masyarakat yang digerakkan oleh nilai-nilai ekonomi sehingga sifat-sifat komunal juga akan tersisih.

Budaya merupakan salah satu faktor yang paling mempengaruhi motif, sikap, intensi dan pembelian (Jarvepaa \& Tracinsky dalam Ozen \& Kodaz, 2012). Dalam penelitian lintas budaya menurut Hofstede (Ozen \& Kodaz, 2012) terdapat lima dimensi nilai budaya yaitu power distance, uncertainty avoidance, individualis-kolektif dan maskulinitasfeminitas. Dari kelima dimensi ini individualis- kolektif menjadi perspektif yang paling penting terhadap motivasi seseorang. Sehingga, budaya berfungsi untuk memahami mengapa anggota dari budaya yang berbeda mempengaruhi motivasi individu di dalamnya.

Hofstede \& Hofstede (2005) dalam penelitiannya mengenai nilai budaya kepada karyawan Indonesia yang bekerja untuk IBM, menggambarkan Indonesia sebagai negara yang kolektivis dan memiliki nilai indeks individualis terkecil di dunia. Pada masyarakat individualis setiap orang bertanggungjawab untuk menjaga dirinya sendiri dan keluarga langsung. Namun dalam masyarakat kolektif, setiap orang merupakan bagian dari kelompok yang saling menjaga, dan diharapkan untuk mengikuti harapan masyarakat dan kelompoknya. Penelitian mengenai nilai-nilai kerja dilakukan oleh Mangundjaya (2013) yang melakukan penelitian kepada karyawan umumnya, hasil yang diperoleh berlawanan dengan hasil yang dikemukakan oleh Hofstede dimana hasil penelitian diperoleh adalah para responden tinggi dalam nilai budaya individualis.

Perubahan yang terjadi di Jakarta sebagai kota industri dan material industrialis menciptakan perubahan sosial yang patut dicermati. Penelitian sebelumnya juga lebih banyak mengkaji budaya dari Amerika dan masih sedikit yang meneliti secara spesifik di perkotaan. Maka dari itu, berdasarkan fenomena yang diperoleh, penelitian ini ingin mengetahui bagaimana gambaran budaya saat ini pada masyarakat kota Jakarta dan keterkaitannya terhadap motivasi belanja hedonik.

\subsection{Tujuan Penelitian}

Tujuan dari penelitian ini adalah untuk mengetahui hubungan budaya individualis-kolektif terhadap motivasi berbelanja hedonis masyarakat kota Jakarta.

\section{TINJAUAN PUSTAKA \\ 2.1 Motivasi Berbelanja Hedonik}

Belanja berdasarkan kesenangan atau hedonic shopping berhubungan dengan senang dan nikmat yang diperoleh dari pengalaman berbelanja dan menghasilkan perasaan gembira (Babin et. al dalam Lee, Kim \& Lee, 2013). Menurut Engel, Blackwell dan Minard (2000) motivasi belanja berdasakan kesenangan adalah motivasi yang berlandaskan respons emosi, kenikmatan sensori, mimpi-mimpi dan pertimbangan estetika.

Konsumsi berdasarkan kesenangan dapat terlihat dari aktivitas rekreasi, olahraga, seni, travel atau area lainnya seperti pertunjukkan dan pendidikan. Konsumsi berdasarkan kesenangan lebih bersifat subjektif dan lebih personal. Konsumen lebih terstimulasi, berpartisipasi dalam proses berbelanja, merasa diri bebas, memiliki motivasi fantasi dan walaupun sementara, melupakan masalah-masalah mereka (Babin et al. dalam Bakirtas \& Divanoglu, 2013).

Menurut Arnold \& Reynolds (Lee,Kim, \& Lee, 2013) , Dimensi-dimensi motivasi belanja berdasarkan hedonic terbagi menjadi enam dimensi, yaitu:
1. Adventure shopping: motivasi berbelanja untuk stimulasi, petualangan, dan perasaan berada di dunia lain. Sehingga berbelanja menjadi solusi yang tepat bagi orang- orang yang mencari petualangan dalam dunia yang berbeda dengan visual, bau dan suara yang menarik. 
2. Gratification shopping: menekankan pada keinginan para pembelanja untuk meningkatkan keadaan suasana hati mereka dengan menggunakan uang dan membeli sesuatu yang bagus. Berbelanja untuk menciptakan perasaan positif, merasa lebih baik atau memberikan perlakuan spesial kepada diri sendiri.

3. Social shopping: motivasi belanja yang berhubungan dengan kenikmatan berbelanja dengan teman-teman dan keluarga.

4. Idea shopping: motivasi belanja yang berhubungan dengan belajar mengenai dan mengikuti tren-tren, produk dan mode terbaru.

5. Role shopping: kesenangan ekstrinsik dan instrinsik yang dirasakan oleh pembelanja ketika menemukan benda-benda yang sempurna untuk orang lain.

6. Value shopping: belanja untuk tawar menawar, mencari produk-produk dengan potongan harga dan menemukan diskon atau harga rendah.

\subsection{Budaya}

Heine (dalam Keith, 2011) menggambarkan dua definisi dari budaya: (1) informasi (keyakinan, kebiasaan dan ide-ide), dipelajari dari orang lain, mampu mempengaruhi tingkah laku; 2). Sekelompok orang-orang yang berbagi hubungan dan pengalaman. Matsumoto (dalam Keith, 2011) mengemukakan definisi komprehensif dari budaya yaitu sebuah makna unik dan system informasi, dibagikan oleh sebuah kelompok dan diteruskan ke generasi sehingga membuat kelompok tersebut dapat memenuhi kebutuhan untuk bertahan hidup, dengan koordinasi perilaku sosial dengan tujuan mencapai eksitensi yang dapat berjalan terus, untuk meneruskan perilaku sosial yang sukses, menggapai kebahagiaan dan memperoleh makna kehidupan.

\subsubsection{Budaya Individualis-Kolektif}

Budaya memberikan dampak besar terhadap pertumbuhan dan perkembangan individu, belajar dari lingkungan sekitarnya. Individualis vs kolektif adalah "sindrom budaya" yang merupakan refleksi dari sikap, keyakinan, kategorisasi, peran dan nilai-nilai yang dibagikan dan dtemukan pada individu-individu yang berbicara bahasa tertentu dan tinggal di daerah geografis tertentu, selama periode sejarah tertentu pula (Triandis et al dalam Cozma, 2011). Hofstede (2011) menjelaskan perbedaan dari budaya individualis vs kolektif. Individu dalam budaya kolektif memperhatikan kesejahteraan dari in- group, meletakkan tujuan dari kelompok dahulu diatas tujuan pribadi dan perilaku mereka diatur oleh norma sosial daripada sikap pribadi. Individu sejak lahir bergabung dalam kohesivitas kelompok yang kuat dan keluarga besar. Sedangkan, individu dalam budaya individualis lebih fokus pada tujuan personal dibandingkan kelompok dan berperilaku sesuai dengan sikap mereka daripada norma dalam masyarakat.

Perbedaan masyarakat individualis dan kolektif adalah sebagai berikut (Hofstede, 2011):

$$
\text { Individualis }
$$

Setiap orang harus
menjaga diri sendiri
dan hanya keluarga
langsung mereka

Kesadaran "saya"

Hak untuk privasi

Mengemukakan pemikiran adalah hal yang sehat.

\section{Kolektif}

Orang-orang yang

lahir di dalam keluarga besar atau marga, yang melindungi mereka sebagai pertukaran untuk loyalitas

\section{Kesadaran "kami”}

Menekankan pada kebersamaan

Harmoni harus dijaga 


\begin{tabular}{ll}
\hline $\begin{array}{l}\text { Orang-orang lain } \\
\text { diklasifikasikan } \\
\text { sebagai individu }\end{array}$ & $\begin{array}{l}\text { Orang-orang lain } \\
\text { diklasifikasikan } \\
\text { sebagai dalam } \\
\text { kelompok (in- } \\
\text { group) atau luar } \\
\text { kelompok (out } \\
\text { group). }\end{array}$ \\
$\begin{array}{ll}\text { Opini pribadi } \\
\text { seseorang diharapkan }\end{array}$ & $\begin{array}{l}\text { Opini-opini } \\
\text { ditentukan oleh } \\
\text { dalam kelompok } \\
\text { (in-group) }\end{array}$ \\
$\begin{array}{l}\text { Pelanggaran terhadap } \\
\text { norma menimbulkan } \\
\text { perasaan bersalah }\end{array}$ & $\begin{array}{l}\text { Pelanggaran } \\
\text { terhadap norma } \\
\text { menimbulkan } \\
\text { perasaan malu }\end{array}$ \\
$\begin{array}{l}\text { Tujuan dari } \\
\text { pendidikan adalah } \\
\text { belajar. }\end{array}$ & $\begin{array}{l}\text { Tujuan dari } \\
\text { pendidikan adalah } \\
\text { bagaimana } \\
\text { melakukan sesuatu }\end{array}$ \\
\hline $\begin{array}{l}\text { Hubungan } \\
\text { didahulukan } \\
\text { daripada tugas }\end{array}$ \\
\hline
\end{tabular}

\footnotetext{
Menurut Triandis (dalam Cozma, 2011), menyatakan bahwa budaya individualis-kolektif merupakan dua pola budaya yang berbeda namunteradpat maam-macam dari budaya individuali dan kolektif itu sendiri. Sebagai contoh, budaya individualis di Amerika berbeda dengan budaya individualis di Swedia. Budaya individualis-kolektif terbagi menjadi dua yaitu horizontal dan vertikal berdasarkan keyakinan individu akan kesetaraan/ ketidaksetaraan antar anggota yang berada di dalam suatu kelompok budaya. Seseorang yang memiliki skor yang tinggi pada dimensi vertikal cenderung menerima ketidaksetaraan dan menekankan prestasi, status, hierarki dan perbandingan dengan orang lain dan kompetisi antar level di dalam sebuah kelompok. Sedangkan individu yang tinggi pada dimensi horizontal mendukung kesetaraan, nilainilai kebebasan untuk diri mereka tanpa harus membandingkan dengan orang lain
}

dan tidak berusaha untuk menjadi lebih baik daripada orang lain (Tiandis \& Gelfand dalam Cozma, 2011). Maka dari itu, budaya individualis-kolektif dengan horizontal-vertikal menjadi kombinasi yang menghasilkan empat konstruk yaitu:

1. Horizontal individualism (HI)

Horizontal individualism memiliki pandangan bahwa setiap individu adalah unik dan setiap orang adalah setara dalam suatu kelompok. Indvidu yang tinggi dalam HI sealu mencari keunikan, kreativitas, otonomi dan sering mengambil resiko sebagai hasil dari konsekuensi kegagalan (Komarraju \& Cokley dalam Pyle, 2011).

2. Vertical Individualism (VI)

Vertical individualism memiliki karakterisik bahwa setiap orang adalah unik daripada orang lainnya dan menciptakan hierarki di dalam kelompok. Diri yang otonom tetap dihargai namun budaya terstruktur secara hierarki berdasarkan status setiap orang.

3. Horizontal Collectivism (HC)

Horizontal Colletivism dikarakteristikan sebagai identifikasi diri yang kuat kepada kelompoknya sendiri (in-group) tanpa membedakan level status. Setiap orang saling bergantung dan kesamaan adalah esensi utama dari pola budaya ini. Struktur ikatan kelompok yang berorientasi pada suasana kekeluargaan.

4. Vertical Collectivism (VC)

Vertical Collectivism merupakan komunitas yang mana setiap orang mementingkan kepentingan kelompok di atas kepentingan pribadi serta mempertahankan hierrki. Budaya VC menekankan saling berbagi dalam komunitas, tingkat otoritas, mempertahankan rasa saling ketergantungan dan rendahnya kebebasan (Sengelis dalam Pyle, 2011).

\section{METODE PENELITIAN}

Dalam penelitian ini, peneliti menggunakan pendekatan kuantitatif karena memungkinkan peneliti untuk 
mengukur respon dari banyak orang dengan sejumlah pernyataan.

Populasi dalam penelitian ini adalah masyarakat yang tinggal di kota Jakarta. Namun, dalam penelitian ini karakteristik usia ini dipertimbangkan berdasarkan penelitian sebelumnya oleh Budisantoso (2006) mengenai motivasi berbelanja di Surabaya. Dari hasil penelitian diketahui rentang usia 18- 24 tahun adalah responden terbanyak dan diikuti dengan usia 25- 29 tahun dan 30- 34 tahun. Maka dari itu, dalam penelitian ini rentang usia dari responden penelitian adalah minimal 17 tahun hingga 40 tahun.

Teknik sampel yang digunakan adalah quota sampling, yang mana peneliti mengambil sampel yang terebar di 5 wilayah Jakarta yang sesuai dengan karakteristik usia dalam penelitian. Jumlah sampel dalam penelitian ini sejumlah 134 orang.

Instrument yang digunakan dalam penelitian ini mencakup dua instrument yaitu skala pengukuran budaya individualis kolektif dan skala motivasi belanja berdasarkan kesenangan. Skala pengukuran individualis dan kolektif yang digunakan adalah " $A$ reduced version of the horizontal and vertical individualism and collectivism scale" yang dimodifikasi dari Sivadas, Bruvold, Nelson (2007). Alat ukur tersebut telah diujicobakan ke empat negara yaitu Amerika, Denmark, China dan India. Budaya invidualis-kolektif terbagi dalam empat tipologi: 1). Horizontal- individualis; 2). Vertikal-individualis; 3). HorizontalKolektif; 4). Vertikal-kolektif.

Motivasi belanja dengan kesenangan menggunakan instrument yang dikembangkan oleh Arnold dan Reynold (2003) yang telah diadaptasi dalam bahasa Indonesia oleh Tjipton, Chandra, yang dimodifikasi oleh peneliti.

Uji coba instrument dilakukan kepada 40 responden. Penghitungan validitas aitem dilakukan dengan batasan uji korelasi antar butir dengan skor butir. Butir-butir yang valid adalah butir-butir yang memiliki nilai corrected item-total correlation di atas 0.3 .

Hasil uji validitas untuk alat ukur motivasi berbelanja hedonik diperoleh butir valid sebanyak 21 butir dari 24 butir dengan rentang validitas 0.347-0.748 dan reliabilitas sebesar 0.912. Pada alat ukur budaya individualis- kolektif diperoleh butir valid sebanyak 10 butir dari 16 butir dengan reliabilitas sebesar 0.771 dan rentang validitas 0.304-0.618. Menurut Azwar (2006) jika nilai reliabilitas kurang dari 0.6 berarti kurang baik, di atas 0.8 adalah baik.

Teknik analisa data yang digunakan dalam penelitian ini adalah uji korelasi. Dalam proses pengolahan data dan pengujian, peneliti menggunakan software SPSS versi 19.

\section{HASIL DAN PEMBAHASAN 4.1 Deskripsi Umum Subjek Penelitian}

Tabel 1.Deskripsi Subjek berdasarkan Usia

\begin{tabular}{lll}
\hline Usia & Frekuensi & Persentase \\
\hline 17-20 tahun & 50 & 37.3 \\
21-30 tahun & 50 & 37.3 \\
$31-40$ tahun & 34 & 25.4 \\
\hline Total & 134 & 100 \\
\hline
\end{tabular}

Dari hasil diperoleh responden dengan kategori usia 17-20 tahun sebanyak 50 orang (37.3\%), usia 21-30 tahun sebanyak 50 orang $(37.3 \%)$ an usia $31-40$ tahun sebanyak 34 orang (25.4\%).

Tabel 2. Deskripsi Subjek berdasarkan Jenis Kelamin

\begin{tabular}{lll}
\hline $\begin{array}{l}\text { Jenis } \\
\text { kelamin }\end{array}$ & Frekuensi & Persentase \\
\hline Laki-laki & 44 & 32.8 \\
Perempuan & 90 & 67.2 \\
\hline Total & 134 & 100 \\
\hline
\end{tabular}

Dalam penelitian ini diperoleh responden laki-laki sebanyak 44 orang (32.8\%) dan perempuan sebanyak 90 orang $(67.2 \%)$. 
Tabel 3. Deskripsi Subjek berdasarkan Pekerjaan

\begin{tabular}{lll}
\hline Pekerjaan & Frekuensi & Persentase \\
\hline $\begin{array}{l}\text { Pelajar/ } \\
\text { mahasiswa }\end{array}$ & 44 & 32.8 \\
$\begin{array}{l}\text { Karyawan/ } \\
\text { karyawati }\end{array}$ & 90 & 67.2 \\
$\begin{array}{l}\text { Ibu rumah } \\
\text { tangga }\end{array}$ & 3 & 2.2 \\
\hline Total & 134 & 100 \\
\hline
\end{tabular}

Dari hasil diketahui jumlah subjek yang bekerja sebagai pelajar sebanyak 44 orang $(32.8 \%)$, karyawan/karyawati sebanyak 90 orang $(67.2 \%)$ dan ibu rumah tangga sebanyak 3 orang (2.2\%).

Tabel 4. Deskripsi Subjek Penelitian Berdasarkan Domisili Di Jakarta

\begin{tabular}{lll}
\hline Domisili & Frekuensi & Persentase \\
\hline Jakarta Barat & 43 & 68.78 \\
Jakarta Pusat & 9 & 25.4 \\
Jakarta Selatan & 16 & 11.9 \\
Jakarta Timur & 19 & 14.2 \\
Jakarta Utara & 47 & 35.1 \\
\hline Total & 134 & 100 \\
\hline
\end{tabular}

Dari data diperoleh sebanyak 43 subjek (68.78\%) berdomisili di Jakarta Barat, 9 subjek (6.7\%) berdomisili di Jakarta Pusat, 16 subjek (11.9\%) berdomisili di Jakarta Selatan, 19 subjek (14.2\%) berdomisili di Jakarta Timur, dan 47 subjek (35.1\%) berdomisili di Jakarta Utara.

Tabel 5. Deskripsi Subjek Penelitian berdasarkan Frekuensi Belanja

\begin{tabular}{lll}
\hline $\begin{array}{l}\text { Frekuensi } \\
\text { belanja }\end{array}$ & Frekuensi & Persentase \\
\hline $1-4$ & 92 & 68.78 \\
$5-10$ & 34 & 25.4 \\
$>10$ & 8 & 6 \\
\hline Total & 134 & 100 \\
\hline
\end{tabular}

Dari data yang diperoleh, frekuensi berbelanja subjek per bulan, 1-4 kali sebanyak 92 subjek (25.4\%), lebih dari 10 kali sebanyak 8 subjek (6\%).

\subsection{Nilai Rata-Rata dan Standar Deviasi Variabel Penelitian}

Tabel 6. Nilai Rata-Rata dan Standar Deviasi

\begin{tabular}{lll}
\hline & $\begin{array}{l}\text { Nilai } \\
\text { rata-rata }\end{array}$ & $\begin{array}{l}\text { Standar } \\
\text { Deviasi } \\
\text { (SD) }\end{array}$ \\
\hline $\begin{array}{l}\text { Motivasi belanja } \\
\text { hedonik }\end{array}$ & 68.29 & 12.21 \\
$\begin{array}{l}\text { Budaya Kolektif } \\
\text { Budaya }\end{array}$ & 18.33 & 2.96 \\
\begin{tabular}{l} 
Individualis \\
\hline
\end{tabular} & 17.29 & 3.36 \\
\hline
\end{tabular}

Dari data nilai rata-rata dan standar deviasi diperoleh secara keseluruhan nilai rata-rata motivasi berbelanja hedonic sebesar $68.29(\mathrm{SD}=12.21)$. Secara umum, budaya kolektif memiliki nilai rata-rata $18.33(\mathrm{SD}=2.96)$ sedangkan budaya indivdualis sebesar 17. $29(\mathrm{SD}=3.36)$. Kecenderungan budaya kolektif pada masyarakat lebih tinggi dibandingkan dengan budaya individualis.

\subsection{Hasil Uji Normalitas}

Uji normalitas data dilakukan dengan menggunakan uji KolmogorovSmirnov. Hasil dari uji KolmogorovSmirnov menunjukkan nilai signifikansi variabel budaya adalah sig (p) $0.018<0.05$ yang berarti data tidak berdistribusi normal. Uji normalitas pada variabel motivasi berbelanja hedonik menunjukkan sig (p) $0.316>0.05$, yang berarti variabel motivasi berbelanja hedonik adalah normal. Maka, dapat disimpulkan data tidak berdistribusi normal.

\subsection{Hasil Uji Korelasi}

Uji korelasi dalam penelitian ini menggunakan uji korelasi Spearman. 
Tabel 7. Hasil Uji Korelasi

\begin{tabular}{|c|c|c|}
\hline \multirow{2}{*}{$\mathrm{N}=134$} & \multicolumn{2}{|c|}{$\begin{array}{l}\text { Motivasi berbelanja } \\
\text { hedonik }\end{array}$} \\
\hline & $\begin{array}{l}\mathrm{r} \text { (koefisien } \\
\text { korelasi) }\end{array}$ & $\mathrm{p}$ \\
\hline Budaya kolektif & 0.187 & 0.031 \\
\hline $\begin{array}{l}\text { a. Horizontal } \\
\text { kolektif }\end{array}$ & 0.189 & 0.028 \\
\hline b. Vertikal kolektif & 0.119 & 0.171 \\
\hline Budaya individualis & 0.164 & 0.059 \\
\hline $\begin{array}{ll}\text { a. Horizontal } \\
\text { individualis }\end{array}$ & 0.460 & 0.38 \\
\hline $\begin{array}{l}\text { b. } \begin{array}{l}\text { Vertikal } \\
\text { individualis }\end{array}\end{array}$ & 0.161 & 0.063 \\
\hline
\end{tabular}

Keterangan: Level signifikansi 0.05

Dari hasil diperoleh nilai korelasi Spearman budaya kolektif dengan motivasi berbelanja hedonik dengan nilai $r=0.187$ dan $\mathrm{p}=0.031<0.05$. Maka, ada hubungan antara budaya kolektif dengan motivasi berbelanja hedonik. Pada budaya individualis dengan motivasi berbelanja hedonic diketahui nilai $\mathrm{r}=0.164$ dan $\mathrm{p}=$ $0.059>0.05$, maka tidak ada hubungan antara budaya individualis dengan motivasi berbelanja hedonik.

Adapun korelasi dimensi vertikal dan horizontal dari budaya individualskolektif. Hasil diketahui dimensi horizontal kolektif ada hubungan dengan motivasi berbelanja hedonik dengan nilai $r=0.189$ dan $p=0.028<0.05$. Sedangkan dimensi lainnya, vertikal kolektif $\mathrm{r}=0.119$ dan $\mathrm{p}=$ $0.171>0.05$, horizontal individualis dengan nilai $\mathrm{r}=0.076$ dan $\mathrm{p}=0.383$, vertikal individualis dengan $\mathrm{r}=0.161$ dan $\mathrm{p}=0.063$, disimpulkan tidak ada hubungan dengan motivasi berbelanja hedonik.

Peneliti melakukan uji analisa lebih lanjut untuk mengetahui hubungan budaya kolektif terhadap dimensi-dimensi berbelanja hedonik.
Tabel 8. Hasil Uji Korelasi Budaya Kolektif dengan Motivasi Berbelanja Hedonik Per Dimensi

\begin{tabular}{|c|c|c|}
\hline \multirow{2}{*}{$\mathrm{N}=134$} & \multicolumn{2}{|c|}{ Budaya Kolektif } \\
\hline & $\mathrm{r}$ & $\mathrm{p}$ \\
\hline $\begin{array}{l}\text { Adventure } \\
\text { shopping }\end{array}$ & 0.127 & 0.145 \\
\hline $\begin{array}{l}\text { Gratification } \\
\text { shopping }\end{array}$ & -0.004 & 0.959 \\
\hline Role shopping & 0.241 & 0.005 \\
\hline Value shopping & 0.176 & 0.042 \\
\hline Idea shopping & 0.095 & 0.276 \\
\hline Social shopping & 0.179 & 0.038 \\
\hline
\end{tabular}

Dari data diperoleh, budaya kolektif berhubungan signifikan dengan role shopping, $\mathrm{r}=0.241$ dan $\mathrm{p}=0.005<$ 0.05 , value shopping dengan $\mathrm{r}=0.176$ dan $\mathrm{p}$ $=0.042<0.05$, social shopping dengan $\mathrm{r}=$ 0.179 dan $\mathrm{p}=0.038<0.05$. Namun, budaya kolektif tidak ada hubungan dengan adventure shopping, gratification shopping dan idea shopping.

\section{SIMPULAN DAN SARAN}

Dari hasil penelitian diketahui bahwa, nilai rata-rata budaya kolektif (mean $=18.33)$ lebih besar daripada budaya individualis $($ mean $=$ 17.29) pada masyarakat di Jakarta. Budaya kkolektif memiliki hubungan yang signifikan terhadap motivasi berbelanja hedonik, sedangkan budaya individualis tidak ada hubungan yang signifikan dengan motivasi berbelanja hedonik pada masyarakat kota Jakarta.

Pada budaya kolektif, dimensi horizontal kolektif ada hubungan yang signfikan dengan motivasi berbelanja hedonik. Namun, pada dimensi vertikal 
kolektif tidak ada hubungan yang signifikan dengan motivasi berbelanja hedonik. Kajian lebih lanjut, diketahui budaya kolektif berhubungan signifikan terhadap dimensi motivasi berbelanja hedonik pada aspek: role shopping, social shopping, dan value shopping.

Motivasi berbelanja hedonik menekankan pada perilaku konsumen dalam berbelanja terkait dengan sensori, fantasi dan aspek emosi dalam pengalaman belanja. Griffin, Babin dan Modianos (dalam Kaul, 2007) persepsi nilai dari berbelanja hedonik bergantung pada: 1) orientasi belanja individu; 2) orientasi budaya; 3) ekonomi dan lingkungan kompetitif. Berbelanja sendiri memiliki motif seperti untuk memuaskan kebutuhan pribadi seperti relaksasi, penghargaan, dan rekreasi dan tidak berarti membeli sesuatu saat berbelanja.

Dari sudut pandang budaya, berbelanja memiliki makna simbolis, asosiasi emosi dan kognitif dan makna ini berbeda dari satu budaya dengan budaya lainnya (Kaul, 2007). Menurut Hofstede (2005), Indonesia merupakan negara kolektif. Sebagai negara kolektif, Indonesia menekankan hubungan jangka panjang dengan anggota-anggota di dalam kelompok. Individu-individu berada dalam keluarga besar dan kolektif yang mana setiap orang mengambil tanggung jawab dari orang lain di kelompoknya selain itu Indonesia juga memiliki tingkat kesetaraan yang rendah dalam suatu masyarakat. Pada budaya kolektif yang berorientasi pada kelompok, akan mencari produk ataupun pengalaman yang mempertahankan keharmonisan, menghindari dampak negatif, menekankan hubungan sosial yang kuat dengan orang lain, dan memenuhi peran sosialnya (Higgins dalam Shavitt, Lee, \& Torelli, 2008).

Pada masyarakat horizontal kolektif dikarakteristikkan dengan individu-individu yang mementingkan kepentingan orang lain atau masyarakat di atas kepentingan pribadi, kemudian mereka juga menekankan kesetaraan antara individu dengan anggota-anggota di dalam kelompoknya. Menurut Singelis (dalam Evanschitzjy, Emrich, Sangtani, Ackfeldt, Reynolds \& Arnold, 2014) menyebutkan bahwa pada masyarakat individualistik seperti di Amerika memiliki hubungan yang kuat terhadap gratification shopping. Sedangkan, konsumen di budaya kolektif merasa kurang baik untuk terlibat dalam self-gratification shopping.

Penelitian kepada 4 negara oleh Evanschitzjy dkk diperoleh, masyarakat kolektif lebih berkorelasi terhadap role shopping, value shopping, dan adventure shopping. Dalam penelitian ini diperoleh hasil budaya kolektif berhubungan secara signifikan dengan role shopping dan berhubungan pula dengan social shopping. Dalam pengalaman berbelanja, individu dengan budaya horizontal kolektif akan lebih mempertimbangkan keluarga, temanteman maupun kelompoknya dibandingkan dirinya sendiri. Mereka termotivasi untuk berbelanja dengan motif rasa senang ketika memperoleh benda-benda yang sempurna dan baik untuk orang lain (role shopping). Pada penelitian sebelumnya oleh Gillison dan Reynold (2016), diketahui bahwa berbelanja dengan tujuan membelikan hadiah menimbulkan perasaan positif, flow, fantasi, kepuasan daripada berbelanja untuk orang lain namun bukan untuk hadiah. Faktor lainnya yang mendukung adalah keberagaman masyarakat Indonesia dan budaya kebersamaan yang kental, perayaan hari-hari raya oleh berbagai suku dan agama cukup banyak pada masyarakat Indonesia yang mana dalam perayaan masyarakat Indonesia memiliki budaya untuk berkumpul-kumpul dengan teman dan keluarga. Hal ini pula yang mendukung motivasi berbelanja hedonik.

Selain itu, budaya kolektif berhubungan dengan social shopping, individu memperoleh rasa senang ketika melakukan belanja dengan suasana ramai, berkumpul bersama teman-teman dan keluarga yang merupakan bentuk dari social shopping. Sosialisasi menjadi motif 
utama ketimbang untuk membeli barang (Arnold \& Reynold, 2003).

Value shopping rasa kepuasan yang diperoleh konsumen ketika memperoleh harga terbaik atau mendapatkan barang dengan harga special promo. Adanya perasaan pencapaian dengan membeli barang dengan harga diskon (Arnold \& Reynold, 2003). Riset yang dilakukan "Nielsen Shopper Trends Report 2012" (dalam Prihtiyani, 2012)menunjukkan sebesar 61 persen konsumen menyukai diskon ketimbang hadiah langsung. Faktor harga juga menjadi pertimbangan terbesar konsumen Indonesia diketahui 59 persen konsumen mempertimbangkan harga barang kebutuhan sehari-hari dan 24 persen mengetahui semua harga kebutuhan seharihari yang mereka beli secara teratur.

\section{SIMPULAN DAN SARAN}

Dari penelitian dapat disimpulkan bahwa masyarakat kota Jakarta memiliki kecenderungan budaya kolektif (mean $=18$. 33) dibandingkan budaya vertikal (mean= 17.29). Hal ini menunjukkan masyarakat kota Jakarta memaknai diri mereka tidak terlepas dengan kelompoknya, kekeluargaan, dan pentingnya keharmonisan dalam kelompok.

Selain itu, ditemukan adanya hubungan antara budaya kolektif dengan motivasi berbelanja hedonik. Sedangkan tidak ada hubungan antara budaya individualis dengan motivasi berbelanja hedonik.

Budaya kolektif diketahui ada hubungan terhadap aspek dimensi role shopping, social shopping dan value shopping. Individu dengan budaya kolektif senang berbelanja dengan tujuan untuk memperoleh benda-benda yang ditujukan untuk orang lain, mengutamakan kepentingan orang lain ketimbang diri mereka. Keinginan untuk berbelanja juga ditekankan untuk sosialisasi sebagaimana budaya kolektif senang dengan suasana keakraban dengan teman dan keluarga. Hal lainnya adalah adanya hubungan dengan motivasi berbelanja untuk memperoleh harga terbaik/ promo.

Saran untuk penelitian selanjutnya, perlu memperhatikan alat ukur budaya individualis -kolektif yang digunakan untuk penelitian. Alat ukur budaya akan lebih baik jika dapat dikembangkan sendiri, dengan pemahaman yang sesuai dengan masyarakat Indonesia. Hal ini dikarenakan, dalam penelitian ini terdapat banyak butir yang gugur. Selain itu, penelitian selanjutnya dapat menambahkan jumlah sampel penelitian lebih banyak agar dapat mewakili populasi penelitian.

Saran bagi masyarakat kota adalah perlu memperhatikan frekuensi pengeluaran dari berbelanja dan menyisihkan sebagian pendapatan untuk kebutuhan jangka panjang. Dalam hal berbelanja, masyarakat kota yang menjadi target market perbelanjaan perlu memperhatikan daya beli mereka dan edukasi untuk menabung dan memanfaatkan pendapatan yang telah dimiliki.

\section{DAFTAR PUSTAKA}

Arnold, M. J., \& Reynolds, K. E. (2003). Hedonic shopping motivations. Journal of Retailing, 79(2), 77-95. doi:10.1016/S0022-4359(03)00007-1

Badan Pusat Statistik. (2014). Statistik daerah provinsi DKI Jakarta. Retrieved from http://jakarta.bps.go.id/backend/pdf_ publikasi/Statistik-Daerah--ProvinsiDKI-Jakarta-2014.pdf.

Cozma, I. (2011). How are individualism and collectivism measured? Romanian Journal of Applied Psychology, 13(1), 11-17.

Engel, J.F, Blackwell R.D., \& Minard P.W. (2000). Perilaku konsumen (Jilid 1). Binarupa Aksara: Jakarta.

Ertekin, O. Z., Bayraktaroglu, G., \& Gurkaynak, N. (2014). Role of 
Shopping Motives, Age and Gender in Evaluating Retail Atmospheric Cues. Asian Journal of Marketing, 8, 24-43.

Evanschitzjy, H., Emrich, O., Sangtani, V. Ackfeldt, A-L., Reynolds, K. E \& Arnold, M. J. (2014). Hedonic shopping motivations in collectivistic and individualistic consumer cultures. Intern. J. of Researach in Marketing, 31, 335-338.

Gillison, S., \& Reynolds, K. (2016). Shopping for yourself versus shopping for someone else. Journal of Marketing, 33(4), 225-234.

Hofstede, G. (2011). Dimensionalizing Cultures: The Hofstede Model in Context. Online Readings in Psychology and Culture, 2(1) at http://dx.doi.org/10.9707/23070919.1014 .

Kaul, S. (2007). Hedonism and culture: Impact on shopping behavior a research agenda. Vikalpa, 32(3), 8189.

Keith, K. D. (2011). Introduction to crosscultural psychology. In Kenneth D. Keith (Ed). Cross-cultural Psychology, 3-19.

Kusuma, G. W., Idrus, S., \& Djauzali, A. The influence of hedonic shopping motivation on buying decision with gender as dummy variable (A study on consumers at the Hardy' Mall Singaraja, Buleleng Regency, Indonesia). European Journal of Business and Management, 5(31), 241- 246.

Lee, M. Y., Kim, Y. K., Lee, H. J. (2013). Adventure versus gratification: Emotional shopping in online auctions. European Journal of Marketing, 47(2), 49-70.
Mazwahid. (2016). Indonesia 2020: Generasi millennial kelas menengah kota. Retrieved from http://www.marketing.co.id/indonesi a-2020-generasi-millenial-kelasmenengah-kota/

Mangundjaya, W. L. (2013). Is there cultural change in the national cultures of Indonesia? In Y. Kashima, E. S. Kashima \& R. Beatson (Eds.), TheCultural Dynamics: Selected Papers from the 2010 Congress of theInternational Association for Cross-Cultural Psychology, pp. 59-68.

Prihtiyani, E. (2012). Konsumen lebih suka diskon dibandingkan dengan hadiah. Retrieved from http://bisniskeuangan.kompas.com/re ad/2012/07/26/16575799/Konsumen. Lebih.Suka.Diskon.Dibandingkan.de ngan.Hadiah

Sivadas, E., Bruvold, N.T., Nelson, M.R. (2008). A reduced version of the horizontal and vertical individualism and collectivism scale: A fourcountry assessment. Journal of Business Research, 61, 201-210.

Shavitt, S., Lee, A. Y., \& Torelli, C. J. (2008). Cross-cultural issues in consumer behavior. In Social Psychology of Consumer Behavior (pp. 227-250). Psychology Press. DOI: $\underline{10.4324 / 9781441605283}$

Sutrisno, M. (2005). Transformasi. In Mudji Sutrisno \& Hendar Putranto (ed), Teori-teori kebudayaan. Yogyakarta: Kanisius.

Tjiptono, F., Chandra, Y., \& Diana, A. (2004). Marketing scales. Yogyakarta: Andi Offset. 